\title{
Removal of Default State-Associated Inhibition during Repetition Priming Improves Response Articulation
}

\author{
Andrew M. Dacks, Michael J. Siniscalchi, and Klaudiusz R. Weiss \\ Department of Neuroscience, Mount Sinai School of Medicine, New York, New York 10029
}

\begin{abstract}
Behavior is a product of both the stimuli encountered and the current internal state. At the level of the nervous system, the internal state alters the biophysical properties of, and connections between, neurons establishing a "network state." To establish a network state, the nervous system must be altered from an initial default/resting state, but what remains unclear is the extent to which this process represents induction from a passive default state or the removal of suppression by an active default state. We use repetition priming (a history-dependent improvement of behavioral responses to repeatedly encountered stimuli) to determine the cellular mechanisms underlying the transition from the default to the primed network state. We demonstrate that both removal of active suppression and induction of neuron excitability changes each contribute separately to the production of a primed state. The feeding system of Aplysia californica displays repetition priming via an increase in the activity of the radula closure neuron $\mathrm{B} 8$, which results in increased bite strength with each motor program. We found that during priming, $\mathrm{B} 8$ received progressively less inhibitory input from the multifunctional neurons B4/5. Additionally, priming enhanced the excitability of B8, but the rate at which B8 activity increased as a result of these changes was regulated by the progressive removal of inhibitory input. Thus, the establishment of the network state involves the induction of processes from a rested state, yet the consequences of these processes are conditional upon critical gating mechanisms actively enforced by the default state.
\end{abstract}

\section{Introduction}

Specific features of stimulus-elicited motor responses are defined not only by the characteristics of the stimulus, but also by the internal state of the organism at the time when the response is being elicited. Within the nervous system, at any given time, the internal state reflects an integrated set of biophysical and synaptic characteristics of neurons that constitute a specific neural circuit. Thus, alterations of these characteristics change the state of the network and thereby modify its output (Devor, 2002; Fontanini and Katz, 2008; Nadim et al., 2008; Berg and Hounsgaard, 2009). A number of studies have shown that the state of the network often depends on the history of its activity and the history of its inputs, both of which can modify endogenous biophysical characteristics of, and synaptic inputs to, motor neurons (Ballo and Bucher, 2009; Ballo et al., 2012; Sakurai and Katz, 2009). Traditionally, investigations of history-dependent plasticity of biophysical and synaptic characteristics treated the initial rested or "default" state as a passive state that did not promote or impede specific behaviors and was differentially altered to promote distinct behaviors. An alternative hypothetical view of the default state, which has not been tested at the cellular level, emerged from

Received Aug. 29, 2012; revised 0ct. 8, 2012; accepted 0ct. 9, 2012.

Author contributions: A.M.D. and K.R.W. designed research; A.M.D. and M.J.S. performed research; A.M.D. and M.J.S. analyzed data; A.M.D., M.J.S., and K.R.W. wrote the paper.

This research was funded by National Institutes of Health Grants NS066587 and NS070583 to K.R.W. We thank Dr.

E Cropper, Dr. J. Jing, Dr. B. Ludwar, and M. Perkins for technical assistance and helpful discussions.

The authors declare no competing financial interests.

Correspondence should be addressed to Dr. Andrew Dacks, Department of Neuroscience, Box 1065, Mount Sinai

School of Medicine, 1 Gustave Levy Place, New York, NY 10029. E-mail: adacks@gmail.com.

DOI:10.1523/JNEUROSCI.4137-12.2012

Copyright $\odot 2012$ the authors $\quad 0270-6474 / 12 / 3217740-13 \$ 15.00 / 0$
PET studies that suggested the presence of an organized baseline default function of the brain that becomes suspended when new states are induced while the organism engages in specific behaviors (Raichle et al., 2001; Raichle and Snyder, 2007). Here, we use Aplysia californica to probe this hypothesis and the role that plasticity of intrinsic excitability and synaptic inputs may play in removing a characteristic of the default state that impedes the establishment of a new network state.

We altered the state of the feeding network of Aplysia; specifically, we made it more ingestive by repeatedly eliciting motor programs through stimulation of the command-like interneuron CBI-2. One major manifestation of increased ingestiveness is an increase of the firing frequency of radula closure neuron B8 in motor programs, thus increasing bite strength relative to motor programs elicited in the default state. We found that the progressive increase of $\mathrm{B} 8$ firing during repeated stimulation of CBI-2 depends on an increase of B8 excitability and on suppression of inhibitory input that B8 receives preferentially when motor programs are elicited in preparations that are in the default state. This indicates that the default network state is by no means physiologically neutral, but rather it incorporates active processes that prevent $\mathrm{B} 8$ from responding as if the network were in a more ingestive state. Repetitive activation of the network eliminates the constraints that the default state imposes on B8's ability to fire at a rate that is characteristic of ingestive behavior. Disinhibition is well established as a gating mechanism for the initiation of motor activity (Lennard et al., 1980; Vu et al., 1993; Perrins et al., 2002; Staras et al., 2003; Ménard and Grillner, 2008). In contrast, our study demonstrates that the removal of inhibition exerted in the default state also shapes the articulation of motor responses. 
A
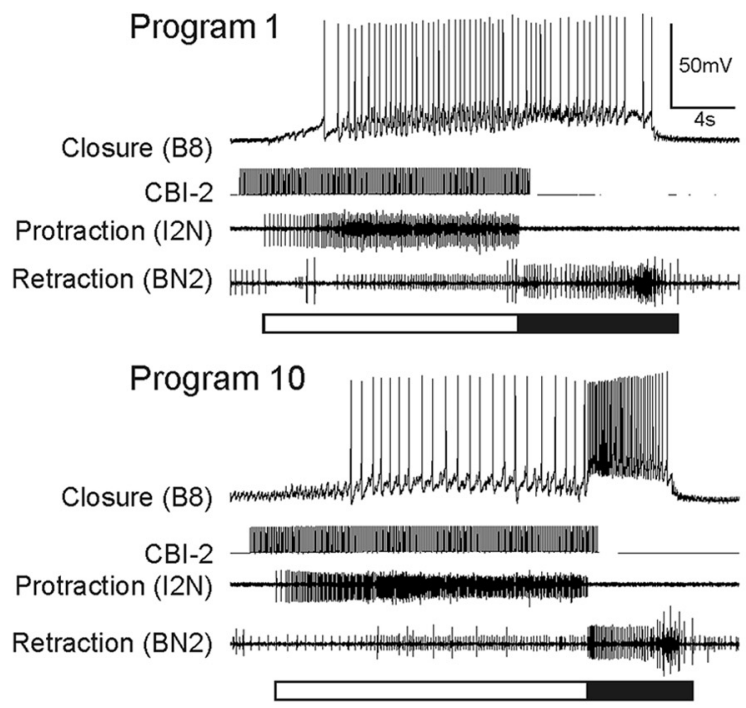

B

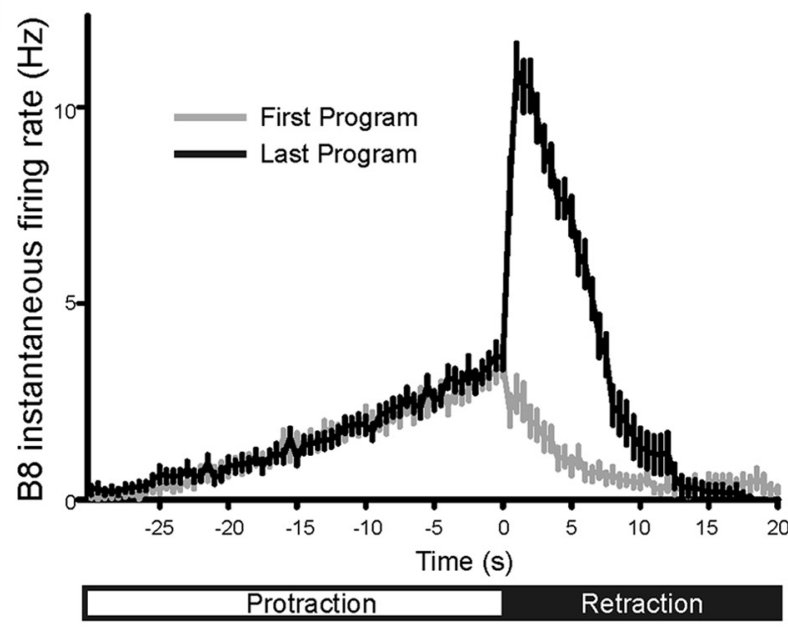

C

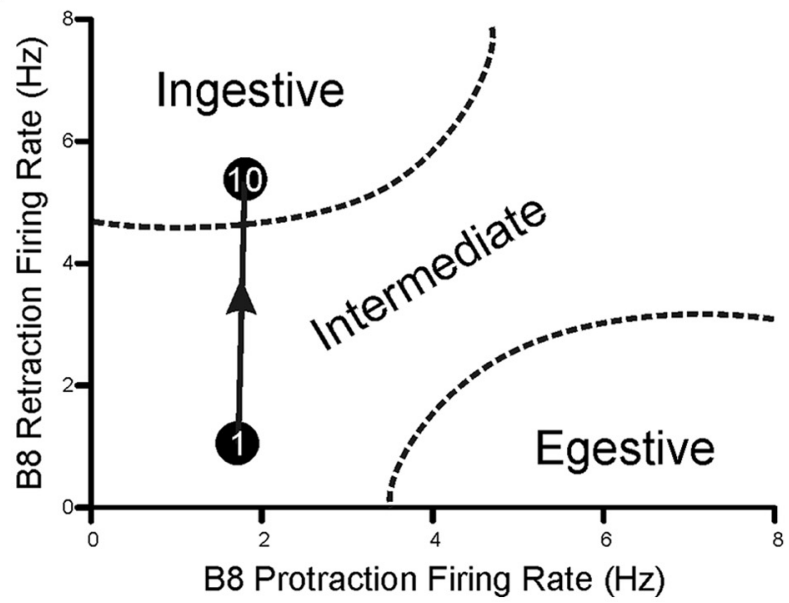

Figure 1. Characterization of ingestiveness of motor programs. A, Typical motor programs elicited at the start ("1st program") and the end ("10th program") of a series of (BI-2 stimulations. The nature of the motor programs is determined by the firing rate of the closure motor neuron B8 during the two program phases: "protraction" (white bar), which is identified by the extracellular activity recorded from the 12 nerve, and "retraction" (black bar), which begins at the end of protraction and lasts until the cessation of activity of the large motor units recorded from buccal nerve 2 (BN2). $\boldsymbol{B}$, Average $B 8$ instantaneous firing rate over protraction and retraction phases during the first (gray) and last (black) programs of a series of (BI-2 stimulations $(n=40)$. C, Plot of the average B8 protraction and retraction firing rate illustrating the cluster boundaries for ingestive, intermediate, and egestive motor programs. In the first ("1") CBI-2 program, average $B 8$ protraction and retraction firing rate are low, resulting in an intermediate

\section{Materials and Methods}

Electrophysiological recordings. Adult sea slugs (Aplysia californica) were obtained from Marinus Scientific and maintained at $14-15^{\circ} \mathrm{C}$. Aplysia are hermaphrodites possessing genitalia of both sexes; therefore, all animals used in this study were of the same sex. Animals were anesthetized with isotonic $\mathrm{MgCl}_{2}$, and all experiments were performed at $14-15^{\circ} \mathrm{C}$. Either artificial sea water (ASW; in mM: $460 \mathrm{NaCl}, 10 \mathrm{KCl}, 55 \mathrm{MgCl}_{2}, 11$ $\mathrm{CaCl}_{2}$, and 10 HEPES buffer, pH7.6), a $2 \mathrm{Mg}^{2+}: 1.25 \mathrm{Ca}^{2+}$ high divalent solution (HiDi; in mM: $368 \mathrm{NaCl}, 10 \mathrm{KCl}, 101 \mathrm{MgCl} 2,13.8 \mathrm{CaCl}_{2}$, and 10 HEPES, pH 7.6; Friedman and Weiss, 2010), or a $3 \mathrm{Mg}^{2+}: 3 \mathrm{Ca}^{2+}$ high divalent solution (3:3 HiDi; in mm: $311 \mathrm{NaCl}, 10 \mathrm{KCl}, 132 \mathrm{MgCl} 2,33$ $\mathrm{CaCl}_{2}$, and $10 \mathrm{HEPES}, \mathrm{pH}$ 7.6) were superfused onto the preparation at $0.3 \mathrm{ml} / \mathrm{min}$. Atropine, hexamethonium, and mecamylamine were all purchased from Sigma. Intracellular recordings were performed with borosilicate electrodes filled with $0.6 \mathrm{~m} \mathrm{K2SO} 4$ and $60 \mathrm{~mm} \mathrm{KCl} \mathrm{electrolyte}$ solution. Electrodes were pulled with a Sutter Instrument Flaming/ Brown micropipette puller and beveled with a stream of aluminum oxide in water to a final resistance of 7-9 MOhm for motor neurons and 10-12 MOhm for interneurons. Electrodes were held in Molecular Devices HS-2A headstages and input to AxoClamp 2B (Molecular Devices) amplifiers. Neurons were identified based on physiological and locational criteria (Gardner and Kandel, 1977; Rosen et al., 1991; Hurwitz and Susswein, 1996; Jing and Weiss, 2002, 2005; Sasaki et al., 2009). Extracellular nerve recordings were performed by aspirating buccal nerve 2, I2 nerve, and the radular nerve into polyethylene tubing. Intracellular and extracellular signals were then amplified by a CyberAmp 380 (Molecular Devices) and sent to a 1320A Digidata (Molecular Devices) for data acquisition. AxoScope version 10 (Molecular Devices) was used to visualize and record experiments. Data were analyzed in Spike 2 (Cambridge Electronic Design) and organized in Excel (Microsoft) for later statistical analyses that were performed in GraphPad Prism version 5.01 (GraphPad Software). Error bars indicate SEM and an alpha of 0.05 was selected for significance tests. When ANOVA tests indicated significant effects, further individual comparisons were calculated with a Bonferroni correction. Normality was tested with using the D'Agostino and Pearson omnibus normality test.

Defining motor programs and identifying neurons. Buccal motor programs (BMPs) result from the coordinated movements of two sets of antagonistic groups of muscles: (1) those muscles that open and close the radula (the mouthparts); and (2) those that protract and retract the radula. Because BMPs always begin with protraction followed by retraction, the functional nature of BMPs depends on the activation of the opener/closer motor neurons in relation to protraction and retraction. Protraction duration was defined as the period of activity of protraction motor neurons recorded extracellularly from the I2 nerve (Hurwitz et al., 1996; Nargeot et al., 1999a,b; Morgan et al., 2000; Jing and Weiss, 2001,2002), while retraction duration was defined as the period of highfrequency activity of large motor units recorded extracellularly from buccal nerve 2 following protraction (Morton and Chiel, 1993a,b; Nargeot et al., 1999a).

If the radula is open during protraction and then closed during retraction, the radula will extend out, clamp down on a food item, and draw it into the mouth. This is referred to as an "ingestive behavior." Over the course of a feeding bout, bite speed and strength progressively increase (Susswein et al., 1978; Weiss et al., 1980). This is associated with an increased output of the radula closure motor neurons at the time the mouthparts are drawn back into the head (Morton and Chiel, 1993a,b). This change in network activity is referred to as "ingestive build-up" or "ingestive priming." Thus, in the isolated nervous system we used the phasing of firing of the radula closure motor neuron B8 to determine whether the motor program was ingestive or intermediate (Fig. 1A). Specifically, if B8 fired at low rates during both protraction and retraction, the program was considered to be intermediate. A progressive increase of B8 firing during the retraction phase was taken as evidence of

$\leftarrow$

motor program. In the final CBI-2 program in a bout of priming ("10"), average B8 retraction firing rate increases, resulting in an ingestive motor program. 
ingestive priming (Proekt et al., 2004). Figure $1 B$ depicts the instantaneous firing rate of $\mathrm{B} 8$ in the first and last motor programs over the course of priming $(n=40)$. Figure $1 C$ depicts the average protraction and retraction firing rate of $\mathrm{B} 8$ over the course of protraction as the motor program nature transitions from being intermediate in nature to ingestive. Thus, the relationship between $\mathrm{B} 8$ protraction and retraction firing rates determines the classification of motor programs as ingestive or intermediate. Because rejection motor programs were not triggered in this study, we do not discuss egestive motor programs further. This level of increase in B8 firing frequency results in a functional closure of the radula in semi-intact preparations (Jing and Weiss, 2005; Friedman et al., 2009), indicating that the priming observed in the isolated nervous system can be used to monitor response priming.

All neurons were identified based on previously published physiological criteria. B8 is a large motor neuron located on the dorsolateral surface of the buccal ganglion, and its spiking activity is monitored by extracellular recording from the radula nerve (Morton and Chiel, 1993b). B4/5 are large cells sitting on the dorsomedial rostral surface of the buccal ganglion and produce one-for-one IPSPs in B8 (Gardner, 1977). B40 is a small interneuron located on the posterior and lateral caudal surface of the buccal ganglion and elicits fast IPSPs and a slow EPSP in B8 (Jing and Weiss, 2002). B34 is a small interneuron located more anteriorly than B40 on the lateral caudal surface of the buccal ganglion and elicits fast IPSPs and a slow EPSP in B8 (Susswein and Byrne, 1988; Hurwitz et al., 1997). B34 and B40 can be distinguished, as B40 has a lower spiking threshold and larger spikes, while B34 has a larger afterhyperpolarization (Jing and Weiss, 2002). B70 is located on the anterior lateral caudal surface of the buccal ganglion and elicits fast IPSPs in B8 (Sasaki et al., 2009). B64 is located on the anterior lateral rostral surface of the buccal ganglion, is strongly active in retraction and is electrically coupled to B4/5 (Hurwitz and Susswein, 1996). B63 is located on the caudal surface of the buccal ganglion near B34 and receives one-for-one fast EPSPs from B34 (Hurwitz et al., 1997). The command neurons CBI-2 and CBI-12 are located in the M-cluster of the cerebral ganglion (Rosen et al., 1991; Hurwitz et al., 1999). Spiking CBI-2 at $10 \mathrm{~Hz}$ initiates protraction within a couple of seconds, and protraction will last on average $20 \mathrm{~s}$, whereas CBI- 12 takes around $10-15 \mathrm{~s}$ to initiate protraction that lasts on average $10 \mathrm{~s}$ (Jing and Weiss, 2005).

Stimulation protocols. Ingestive priming was induced by firing the command-like interneuron CBI-2, which initiates BMPs (Rosen et al., 1991) for the duration of protraction at $\sim 10 \mathrm{~Hz}$ with $15 \mathrm{~ms}$ DC pulses eliciting one-for-one action potentials (Friedman and Weiss, 2010). CBI-2 stimulation was repeated $30 \mathrm{~s}$ after the termination of protraction in the previous program for a total of 10 programs. To induce the persistent change in $\mathrm{B} 8$ excitability in $\mathrm{HiDi}, \mathrm{CBI}-2$ was stimulated 10 times at $10 \mathrm{~Hz}$ for $20 \mathrm{~s}$, with $30 \mathrm{~s}$ between each stimulus train. The same stimulation protocol was used to test the effects of repeated CBI-12 and B63 BMPs on B8 excitability, with the exception that B63 was stimulated at $15 \mathrm{~Hz}$.

To probe B8 excitability, B8 was injected 5 times with a 1 min interstimulus interval with direct current (DC) sufficient to elicit 4, 7, or 15 spikes over $4 \mathrm{~s}$. The same amount of DC was then injected into B8 after repeated CBI-2 programs to gauge any changes in excitability. Excitability was defined by the latency to the first spike and the number of spikes elicited by a current pulse injection. For B4/5 hyperpolarization experiments, B4/5 was hyperpolarized immediately after the onset of retraction to avoid interfering with proper phasing due to the electrical coupling between B4/5 and B64 (Hurwitz and Susswein, 1996). Furthermore, B4/5 display a significant rebound, so the hyperpolarizing current was relieved gradually.

\section{Results}

Priming results in a progressive disinhibition of motor neuron activity

To examine the cellular basis for the transition from the default state, we used the repetition priming paradigm that has been established in the feeding central pattern generator of Aplysia (Proekt and Weiss, 2003; Proekt et al., 2004,2007; Friedman et al.,

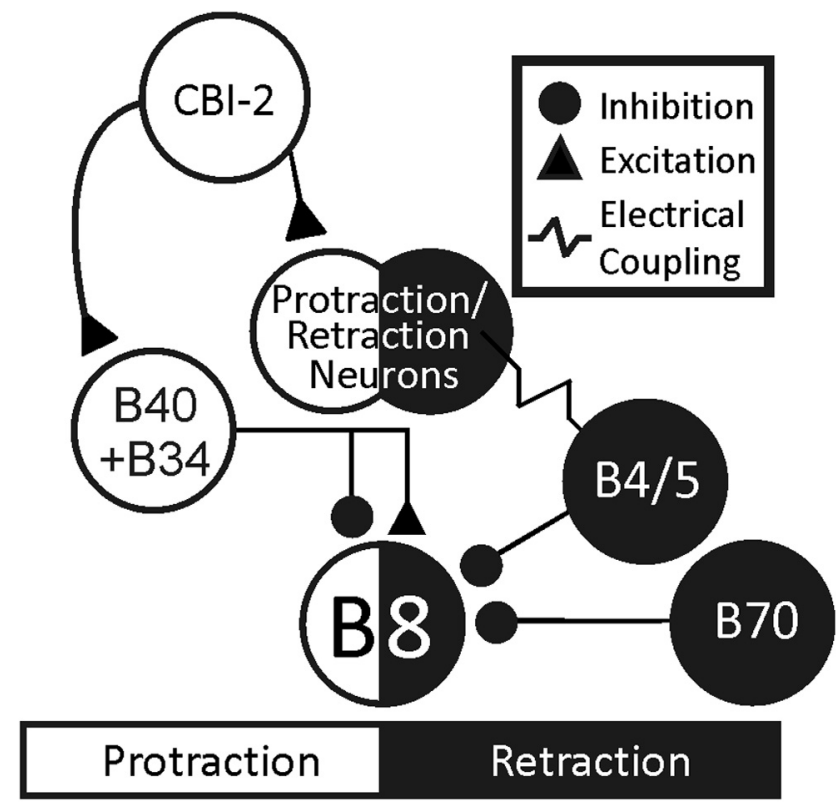

Figure 2. Simplified circuit diagram of the inputs that B8 receives during CBI-2 elicited biting motor programs. (BI-2 ("Command Neuron") directly activates the protraction interneurons B34 and B40, which provide fast inhibitory input to B8 during protraction and a slow EPSP during retraction phase. Because $C B I-2$ initiates programs and the inhibitory neurons $B 4 / 5$ and $B 70$ are activated during retraction phase, $\mathrm{CBI}-2$ also indirectly activates $\mathrm{B} 4 / 5$ and $\mathrm{B} 70$, which suppress $\mathrm{B} 8$ activity during retraction phase.

2009; Friedman and Weiss, 2010). Repeated stimulation of the command neuron CBI-2 causes programs to become progressively more "ingestive," with the activity of the radula closure motor neuron B8 increasing during the retraction phase (Proekt et al., 2004). Figure 2 depicts a simplified circuit diagram of the neurons that provide input to B8 during CBI-2 elicited motor programs. In addition to initiating protraction, CBI-2 activates the protraction interneurons B40 and B34, which elicit fast IPSPs in $\mathrm{B} 8$ during protraction and a slow EPSP that is expressed during retraction after B40 and B34 stop spiking (Jing and Weiss, 2002). In addition, the retraction phase neurons $\mathrm{B} 4 / 5$ provide inhibitory drive to B8 during retraction phase (Kabotyanski et al., 1998; Jing and Weiss, 2001; Sasaki et al., 2009). Thus, the balance between the input from $\mathrm{B} 40 / \mathrm{B} 34$ and $\mathrm{B} 4 / 5$ to $\mathrm{B} 8$ during retraction to a large extent determines the nature of the program elicited.

The increase in $\mathrm{B} 8$ retraction phase firing rate induced by repeated CBI-2-elicited motor programs could be mediated by two general mechanisms: (1) a removal of inhibitory input, suggesting that the default state actively controls network output; or (2) an increase in the excitability of B8 or neurons that provide excitatory synaptic drive to B8, suggesting that the default state is a passive state from which network state-associated changes are induced. We began by examining the activity of neurons that provide inhibitory synaptic input to $\mathrm{B} 8$ during retraction phase, B4/5 and B70. B4/5 elicit IPSPs in the ipsilateral B8 (Gardner and Kandel, 1977) and can suppress B8 retraction firing rate during the first half of retraction (Kabotyanski et al., 1998; Jing and Weiss, 2001; Sasaki et al., 2009). B70, while less potent than B4/5, can reduce $\mathrm{B} 8$ firing during the latter half of retraction (Sasaki et al., 2009). We therefore recorded the activity of B4/5 and B70 during CBI-2-induced build-up. Initially, B8 retraction activity is low while $\mathrm{B} 4 / 5$ has a high firing rate during retraction (Fig. $3 \mathrm{~A}$ ). After $10 \mathrm{CBI}-2$ programs, B8 retraction firing rate increases, while $\mathrm{B} 4 / 5$ retraction firing rate drops dramatically (Fig. $3 A$ ). 

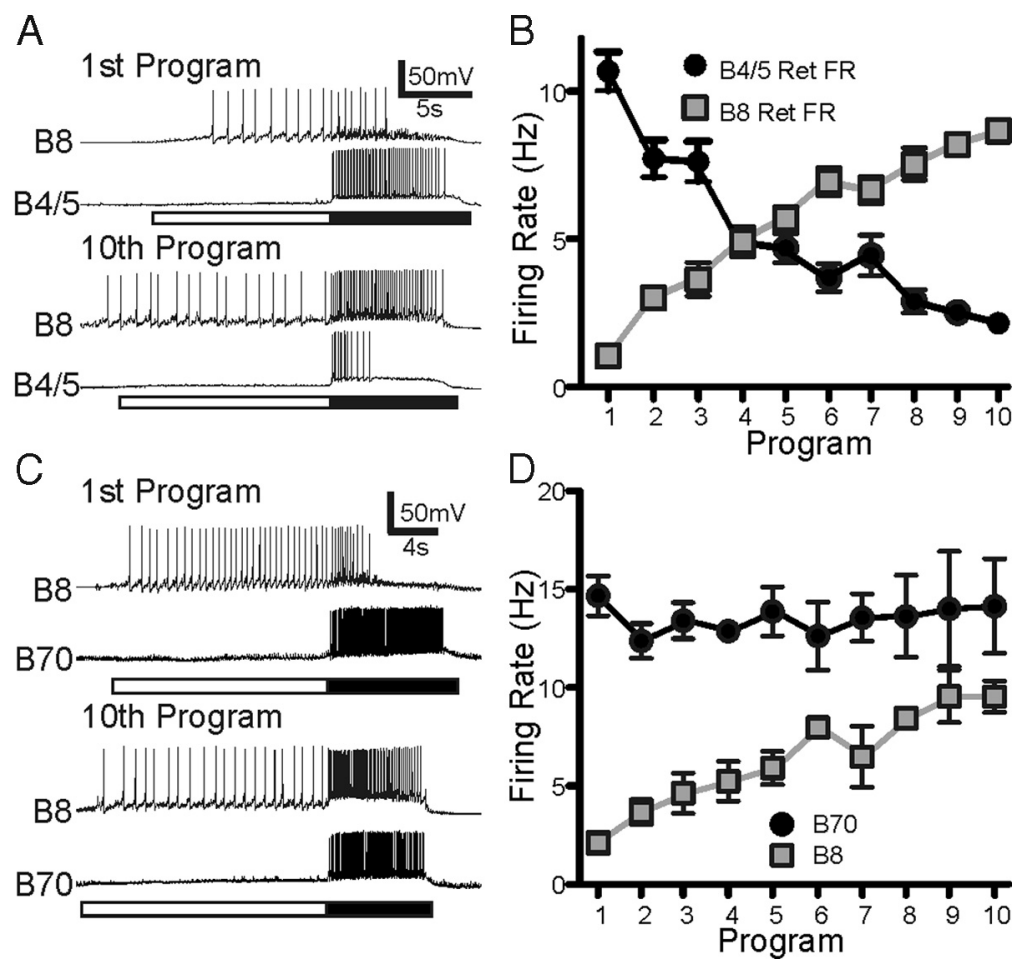

Figure 3. The firing rates of the inhibitory neurons $B 4 / 5$, but not $B 70$, decrease markedly over the course of priming. $A$, Example of $B 4 / 5$ activity during the 1 st and 10th $\mathrm{CBI}-2$ programs over the course of priming. $\boldsymbol{B}$, The average $\mathrm{B} 4 / 5$ retraction firing rate decreases over the course of priming. $C$, Example of B70 activity during the 1st and 10th CBI-2 programs over the course of priming. $D$, The average $B 70$ retraction firing rate does not change over the course of priming.

Figure $3 B$ summarizes the decrease in $B 4 / 5$ retraction firing rate $(10.68 \pm 0.66 \mathrm{~Hz}$ SEM to $2.15 \pm 0.35 \mathrm{~Hz}$ SEM; $n=23)$ and the concomitant increase in B8 firing rate. In contrast to B4/5, B70 retraction firing rate remains relatively stable over the course of build-up (Fig. 3C). Figure 3D summarizes the average course of $\mathrm{B} 70$ retraction firing rate $(14.67 \pm 1.75 \mathrm{~Hz}$ SEM to $14.15 \pm 4.17$ $\mathrm{Hz}$ SEM; $n=3$ ) during CBI-2 build-up. These results indicate that over the course of CBI-2 priming, $\mathrm{B} 8$ receives decreasing inhibitory input from $\mathrm{B} 4 / 5$ during retraction phase. Thus, the default state of the system involves active suppression of motor output that is progressively removed with repeated motor programs.

The decrease in B4/5 activity in CBI-2-elicited programs suggested that B4/5 may gate the activity of B8 during retraction, thus providing a synaptic control mechanism to allow for the increase in B8 activity over the course of priming. We therefore sought to determine the relative contribution of B4/5 to the expression of the ingestive state over the course of priming. We induced priming by eliciting $10 \mathrm{CBI}-2$ programs, then elicited an 11 th program in which the ipsilateral B4/5 were depolarized with a constant current injection to produce a firing rate similar to that of the first program. Finally a 12th program was elicited as a "recovery" control in which the depolarization of B4/5 was removed (Fig. 4A). Thus, if the disinhibition of B8 during retraction was the sole mechanism underlying the change in B8 activity, returning B4/5 firing rate to prepriming levels should reduce B8 retraction firing rate to prepriming levels.

Figure $4 B$ depicts a typical example of this experiment. Initially, B8 retraction firing rate increased dramatically from prepriming (program 1) to postpriming levels (program 10), whereas $\mathrm{B} 4 / 5$ retraction firing rate did the opposite. $\mathrm{B} 8$ retraction firing rate decreased when B4/5 were depolarized (program 11) and returned to postpriming levels when the depolarization of $\mathrm{B} 4 / 5$ was relieved (program 12) (Fig. 4B). Because B4/5 and B70 affect $\mathrm{B} 8$ activity during different portions of retraction phase, $\mathrm{B} 8$ retraction firing rate was calculated for each quadrant of retraction phase (Fig. 4B; "Q1-4"). For each quadrant, one-way ANOVAs with Bonferroni corrections were used to compare $\mathrm{B} 8$ retraction firing rate during the 1st, 10th, 11th, and 12th programs. Significant interactions were found for all four quadrants (Fig. $4 C ; F_{(3,28)}=55.59,109.0$, 39.34 , and 3.861 for quadrants $1-4$, respectively; $n=8$ ). $\mathrm{B} 8$ retraction firing rate was highest postpriming (programs 10 and 12) during the first two quadrants and then decreased substantially during the final two quadrants. This indicates that B8 firing rate became most elevated during the portion of retraction in which B4/5 activity had been strongest before CBI-2 priming. Returning the $\mathrm{B} 4 / 5$ firing rate to its prepriming level through depolarizing current injections (program 11) decreased B8 retraction firing rate to levels significantly lower than after priming (program 10) and the recovery from B4/5 depolarization (program 12) during the first three quadrants (Fig. 4C). Importantly however, when B4/5 were depolarized, B8 retraction firing rate was still significantly higher compared to prepriming levels (program 1). To ensure that the $\mathrm{B} 4 / 5$ retraction firing rates were equivalent prepriming (program 1) and when B4/5 were depolarized postpriming (program 11), we performed a repeated-measures ANOVA with a Bonferroni correction comparing B4/5 retraction firing rate during the 1st, 10th (post-buildup), 11th (B4/5 depolarized), and 12th (B4/5 recovery) programs. While $\mathrm{B} 4 / 5$ retraction firing rate was significantly different between programs $1 / 11$ and programs $10 / 12$ (Fig. $4 D ; F_{(3,60)}=$ $43.83 ;{ }^{\star * \star} p<0.001, n=16 \mathrm{~B} 4 / 5$ s from 8 animals), B4/5 retraction firing rate was not significantly different between the 1 st and 11th programs, nor was it different between the 10th and 12th programs. Thus, the differences between $\mathrm{B} 8$ retraction firing rate observed prepriming and postpriming with B4/5 depolarized (Fig. 4C) were not due to discrepancies in B4/5 firing rate. This suggests that while the decrease in B4/5 activity strongly contributes to the increase in B8 retraction activity during priming, it does not completely account for the change in B8 activity, and therefore an additional mechanism is likely to be involved. Thus, the transition from the default to the primed state involves both the inactivation of processes present in the default state and the induction of processes associated with the primed state.

\section{Priming does not affect the firing rate of neurons providing excitatory drive to $\mathrm{B} 8$}

We next sought to determine whether the transition to the primed state involved the induction of processes from the default state. We began by determining whether there were any marked increases in the activity of neurons that provide either phasic or delayed excitatory drive to $\mathrm{B} 8$ during retraction phase. We measured the firing rates of B40, B34, and B64, all of which provide excitatory drive to B8 during retraction (Hurwitz and Susswein, 
1996; Jing and Weiss, 2002) over the course of CBI-2 priming. B40 protraction firing rate changed only marginally (Fig. $5 A, B$; from $7.33 \pm 0.66 \mathrm{~Hz}$ SEM to $8.14 \pm$ $0.67 \mathrm{~Hz}$ SEM; $n=16$ ) relative to the increase in $\mathrm{B} 8$ retraction rate firing (from $2.4 \pm 0.55 \mathrm{~Hz}$ SEM to $7.11 \pm 0.79 \mathrm{~Hz}$ SEM) over the course of priming. B34 protraction firing rate also changed very little (Fig. 5C,D; $11.92 \pm 0.77 \mathrm{~Hz}$ SEM to $11.27 \pm 0.88 \mathrm{~Hz}$ SEM; $n=15)$, as did B64 retraction firing rate (Fig. $5 E, F ; 8.83 \pm$ $0.48 \mathrm{~Hz}$ SEM to $10.60 \pm 0.68 \mathrm{~Hz}$ SEM; $n=6)$.

Priming induces an increase in motor neuron excitability

We next sought to determine whether CBI-2 priming induced a change in the excitability of B8. Baseline B8 excitability was probed with $4 \mathrm{~s}$ constant current pulses to elicit $\sim 4,7$, or 15 spikes $(n=10$, 13,22 , respectively). CBI-2 priming was then induced and B8 excitability was probed postpriming by injecting the same amount of current as during the baseline measures (Fig. 6A). The latency to first spike was significantly reduced across all three levels of current injection [478.3 \pm $94.68 \mathrm{~ms}$ to $228.1 \pm 26.7 \mathrm{~ms} \mathrm{SEM}, t=2.835$, degrees of freedom $(\mathrm{df})=9, p<0.05$ for 4 spikes; $219.4 \pm 23.3 \mathrm{~ms}$ to $140.6 \pm 11.76 \mathrm{~ms}$, $t=5.102, \mathrm{df}=12, p<0.001$ for 7 spikes; $115.4 \pm 17.4 \mathrm{~ms}$ to $63.10 \pm 3.6 \mathrm{~ms}, t=$ 3.094, df $=21, p<0.01$ for 15 spikes]. More importantly from the viewpoint of this study, the number of spikes elicited from B8 at all levels of DC injection increased after CBI-2 priming (Fig. 6B). Paired $t$ tests revealed a significant increase in the number of spikes elicited at each level of stimulation (Fig. 6C; $t=$ $5.373,7.832$, and 11.31, respectively; $\mathrm{df}=$ 9,12 , and 21, respectively; $p<0.001$ for all). Figure $6 D$ shows the timeline of the enhancement of B8 excitability, which is highest immediately after priming and returns to baseline after $\sim 30 \mathrm{~min}$. Thus, the transition of B8 from the default state to the primed state appears to involve two processes, one that inactivates extrinsic inhibitory inputs to B8, and one that increases intrinsic excitability of B8.

Neither protraction nor retraction interneurons mediate the priming-induced increase in motor neuron excitability

Since CBI-2 programs activate many neurons (both during protraction and retraction), we sought to determine which neurons were responsible for the change in B8 excitability. To narrow down the
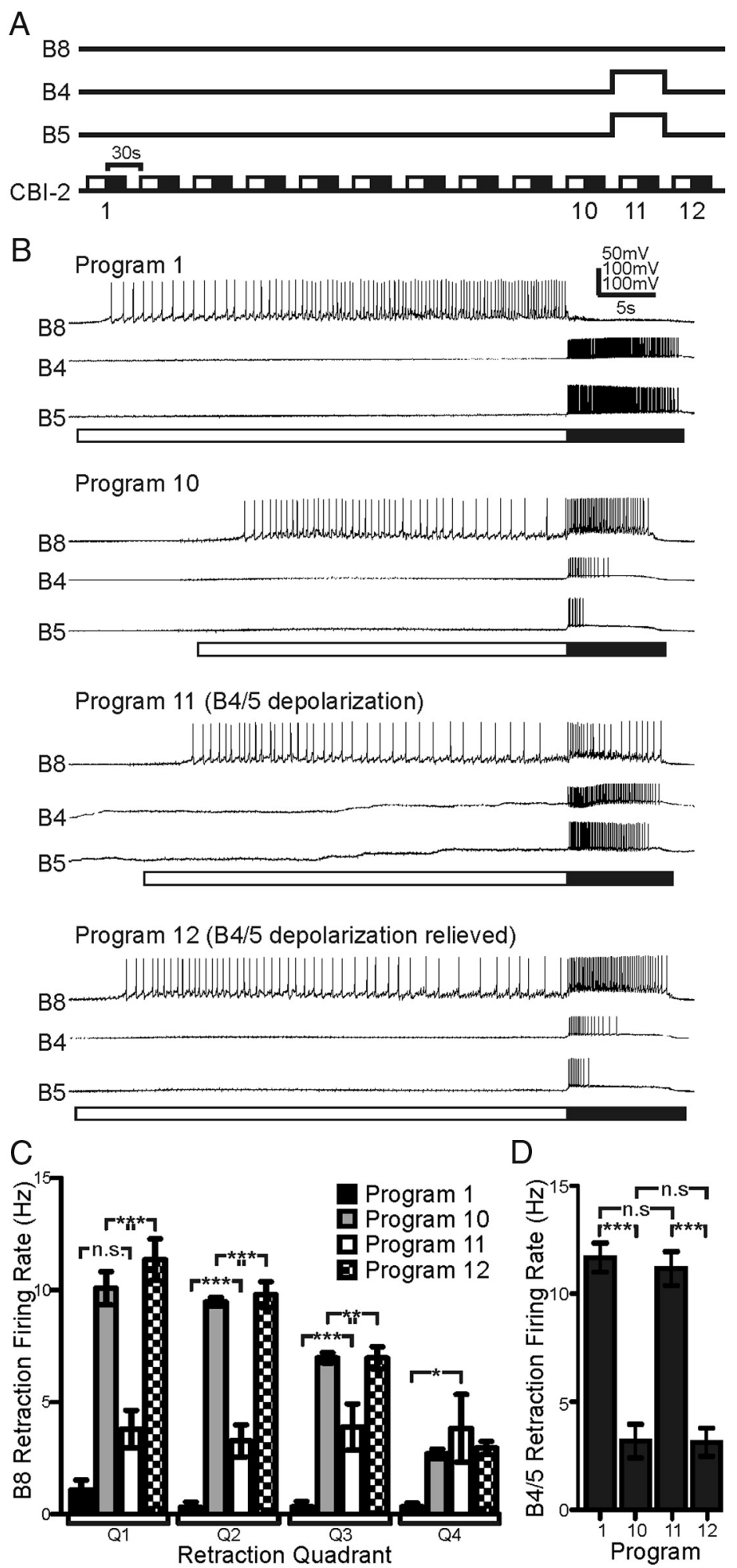

Figure 4. A decrease in default state inhibition contributes to priming of motor responses. $A$, Experimental protocol. CBI-2 priming is induced by eliciting $10 \mathrm{CBI}-2$ programs resulting in the increase in $\mathrm{B} 8$ excitability and the drawdown of $B 4 / 5$ retraction firing rate. An 11th $\mathrm{CBI}-2$ program is elicited in which $\mathrm{B} 4 / 5$ are depolarized to fire at the similar frequency as program 1, before CBI-2 priming was induced. A 12th CBI-2 program is elicited to ensure that the depolarization of $B 4 / 5$ did not persistently alter the network activity. $\boldsymbol{B}$, Biting motor programs elicited by $\mathrm{CBI}-2$ (Program 1 ) are initially egestive or intermediate, but after repeated (BI-2 programs they become ingestive (Program 10). Depolarizing B4/5 to increase their firing rate during retraction decreases B8 retraction firing rate (program 11), which recovers when B4/5 are no longer depolarized during programs (Program 12). C, B8 firing rates during the first three quadrants of retraction are significantly decreased by depolarizing $B 4 / 5$, yet they are still significantly higher than before priming. $D, B 4 / 5$ retraction firing rates are significantly lower during programs 10 and 12 compared to programs 1 and 11 , but do not differ between programs 1 and 11 and between programs 10 and $12\left({ }^{*} p<0.05,{ }^{* *} p<0.01,{ }^{* * *} p<0.001\right)$. 

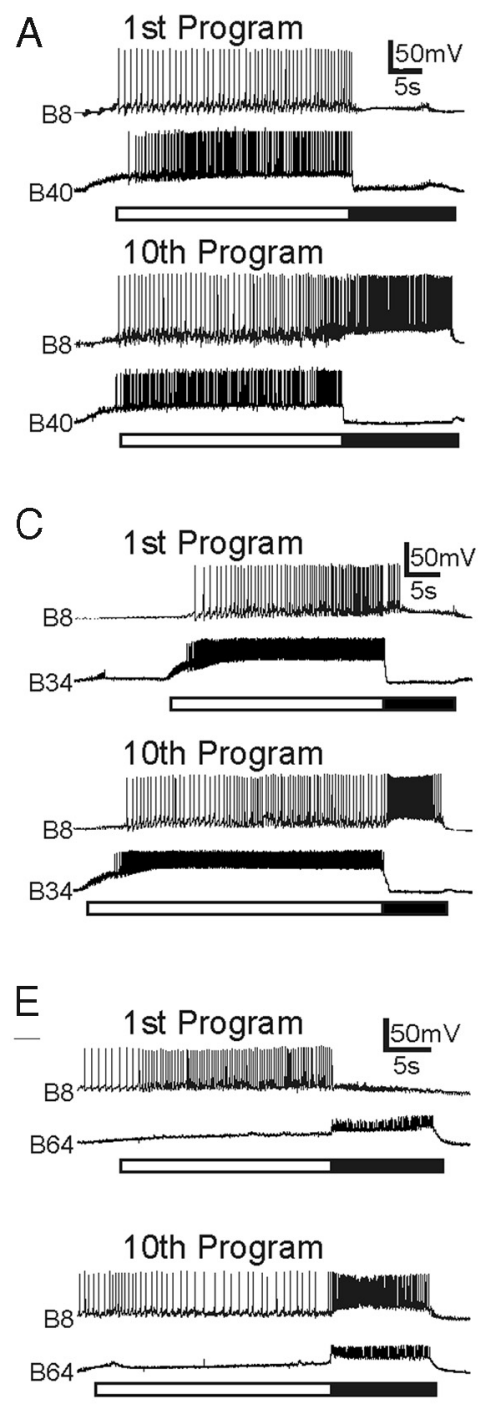
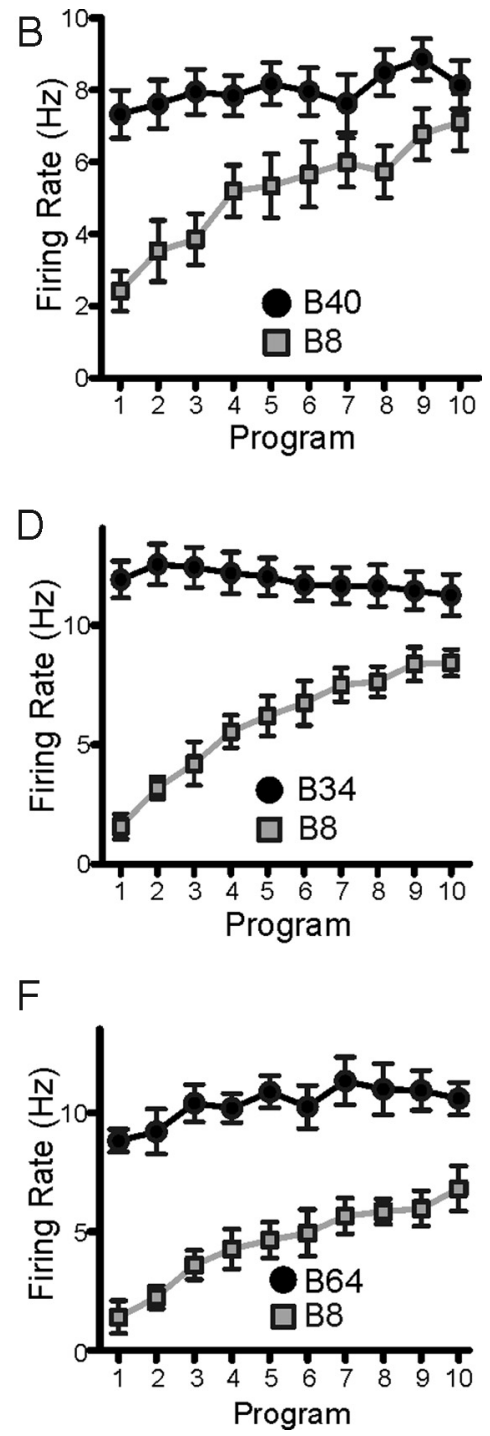

Figure 5. The excitatory inputs to $B 8$ do not change their firing rate during priming. $A$, Example of $B 40$ activity in the 1st and 10th CBI-2 programs during priming. $B$, The average $B 40$ protraction firing rate increases slightly during priming. $C$, Example of B34 activity in the 1st and 10th CBI-2 programs during priming. D, The average B34 protraction firing rate decreases slightly during priming. $\boldsymbol{E}$, Example of $\mathrm{B} 64$ activity in the 1st and 10th CBI-2 programs during priming. $\boldsymbol{F}$, The average $\mathrm{B} 64$ retraction firing rate increases slightly during priming.

number of candidate neurons causing the enhancement of B8 excitability, we repeatedly stimulated CBI-2 (simulating the conditions that elicit priming) while superfusing HiDi onto the preparation. CBI-2 stimulation in HiDi reliably triggers protraction, but rarely results in retraction. As with ASW, stimulation of CBI-2 in HiDi enhanced B8 excitability (Fig. $6 C$; paired $t$ test; $t=$ 8.016 , df $=10, p<0.001 ; n=11$ ), suggesting that neurons activated during retraction are not likely to underlie the modulation of B8 excitability during CBI-2 priming.

To test whether simply triggering buccal motor programs alters B8 excitability, we probed B8 excitability before and after stimulating B63 (which recruits numerous protraction neurons such as B31/32 and B61/62) to trigger 10 motor programs. Stimulating B63 did not significantly affect the number of spikes elicited from B8 by a $4 \mathrm{~s}$ constant current pulse (from $14.79 \pm 0.16$ to $12.63 \pm 1.7$ spikes; paired $t$ test; n.s., not significant; $n=4$ ), suggesting that the protraction neurons active in all motor programs are unlikely to mediate the increase in B8 excitability induced by repeatedly triggering CBI- 2 motor programs.
Two interneurons, B34 and B40, fire robustly during the protraction phase of CBI-2-elicited programs and elicit slow EPSPs in B8. These EPSPs persist into retraction phase and contribute significantly to $\mathrm{B} 8$ retraction firing rate during CBI-2 programs (Jing and Weiss, 2002). We therefore tested whether the participation of B40 or B34 was necessary for the induction of CBI-2 priming by bilaterally hyperpolarizing either B40 or B34. We induced priming by triggering $10 \mathrm{CBI}-2$ programs (control) and then, after a recovery period, we triggered $10 \mathrm{CBI}-2$ programs with both B40s or B34s hyperpolarized (hyperpolarization) and again with both B40s or B34s permitted to fire (recovery). Because bilateral hyperpolarization of B40 causes CBI-2 programs to become intermediate (Jing and Weiss, 2002), we had to ascertain that the expression of persistent changes in program nature were not being masked by the immediate effects of $\mathrm{B} 40$ on $\mathrm{B} 8$ retraction firing rate. We therefore elicited an 11th CBI-2 program in which both B40s were permitted to fire. Unlike B40, B34 does not bias motor programs toward ingestiveness (Jing and Weiss, 2002), so an 11th program in which both B34s were permitted to fire was unnecessary. Figure $7 A$ depicts examples of the first and last programs over the course of ingestive build-up in all three conditions (control, B40 hyperpolarization, and recovery). During the first round of build-up, B8 retraction firing rate increased, and both B40s fired robustly during the protraction phase of every program. When both B40s were hyperpolarized for $10 \mathrm{CBI}-2$ programs, B8 retraction firing rate still increased, although to a lesser extent than during the control or recovery phases (Fig. $7 B$ ). When an 11 th program was triggered in which both $\mathrm{B} 40$ s were able to spike, B8 retraction firing rate was indistinguishable from the 10th CBI-2 programs of the control and recovery groups. The $X Y$ plot in Figure $7 C$ depicts $B 8$ retraction and protraction firing rates during the first and last programs during priming. While bilateral hyperpolarization of both $\mathrm{B} 40$ s increased $\mathrm{B} 8$ protraction firing rate during the first program (one-way ANOVA; $F_{(2,12)}=9.11 ; p<0.01 ; n=5$ ) due to the lack of fast inhibitory input from B40 (Jing et al., 2003), there was no effect on $\mathrm{B} 8$ retraction firing rate during the final program (one-way ANOVA; n.s.; $n=5$ ). Furthermore, in all treatments $\mathrm{CBI}-2$ priming increased $\mathrm{B} 8$ excitability (one-way ANOVA; $\left.F_{(5,24)}=7.643 ; p<0.001 ; n=5\right)$, and these increases did not differ between treatments (Fig. 7D). For bilateral hyperpolarization of $\mathrm{B} 34$, the time course of the increase in $\mathrm{B} 8$ retraction firing rate did not differ between the treatments (Fig. $7 E$ ), although $\mathrm{B} 8$ retraction firing rate was higher during the final program of the recovery treatment (Fig. 7F; one-way ANOVA; $\left.F_{(2,17)}=5.75 ; p=0.02 ; n=6\right)$. Similar to the B40 results, B8 excitability increased regardless of B34 participation in motor 
programs (one-way ANOVA; $F_{(5,36)}=$ $14.37 ; p<0.001 ; n=6)$, and the magnitude of the increases were not statistically different (Fig. 7G). Thus, neither B40 nor $\mathrm{B} 34$ were necessary for the changes in B8 excitability induced by priming.

\section{CBI-2 contributes to the priming- induced increase in motor neuron excitability}

We next examined whether CBI-2 directly contributes to the increase in B8 excitability. Although not previously reported, we started by testing whether CBI- 2 makes a direct synaptic connection with B8. In 3:3 HiDi (see Materials and Methods) we briefly (2-3 s) injected DC into CBI-2 and monitored the activity of B34 and B61 to ensure that CBI-2 triggered facilitating PSPs without initiating protraction. Brief spiking of CBI-2 induced a slow depolarization of $\mathrm{B} 8$ that lasted for $5-10 \mathrm{~s}$ and summated over a long timescale (Fig. 8A). The magnitude of the elicited slow depolarization increased when we depolarized $\mathrm{B} 8$ via $\mathrm{DC}$ injection (Fig. $8 B, C$ ).

The primary transmitter of CBI-2 is acetylcholine (Hurwitz et al., 2003). CBI-2 also releases neuropeptides FCAP and CP2, which increase the excitability of other motor neurons (Koh et al., 2003; Friedman and Weiss, 2010). However, CBI-2 is unlikely to increase B8 excitability via the neuropeptides. FCAP and CP2 do not affect B8 excitability on their own (Friedman and Weiss, 2010), and we found that stimulating the command neuron CBI-12, which also releases FCAP and CP2 (Morgan et al., 2000; Vilim et al., 2001; Koh et al., 2003), does not affect B8 excitability (14.48 \pm 0.24 spikes SEM to $14.45 \pm 0.83$ spikes SEM post CBI-12 stimulation; n.s.). Repeated activation of muscarinic-like receptors has been demonstrated in other invertebrate systems to prime behavioral output (Heinrich et al., 2001; Wenzel et al., 2002). Attempts to induce the increase in B8 excitability with the application of cholinergic agonists were unsuccessful as these agonists robustly elicited network activity, making stable excitability measures impossible. Therefore, we tested whether blocking cholinergic receptors could affect the ability of CBI-2 to enhance B8 excitability. We found that the slow depolarization of B8 by CBI-2 was blocked in the presence of $1 \mathrm{~mm}$ atropine (Fig. $8 D$ ), which reduced the PSP size from $3.77 \pm$ $1.66 \mathrm{mV}$ to $0.16 \pm 0.16 \mathrm{mV}$ (Fig. $8 E$; one-way $\operatorname{ANOVA} ; F_{(2,6)}=$ 20.27; $p<0.01 ; n=4)$, suggesting that the slow depolarization is due to the activation of a cholinergic receptor. Finally, we tested whether atropine could block the ability of repeated CBI-2 stimulation to increase B8 excitability. In $1 \mathrm{~mm}$ atropine, CBI-2 induces only a small residual depolarization of protraction interneurons. Under these conditions, repeated activation of CBI-2 no longer induces the increase in B8 excitability (one-way ANOVA; n.s.; $n=5$ ), whereas the excitability changes were induced during the control phase (one-way ANOVA; $F_{(2,6)}=12.17 ; p<0.01 ; n=5$ ) and after washout (one-way ANOVA; $F_{(2,6)}=5.41 ; p<0.05 ; n=$ 5 ) of atropine (Fig. $8 F$ ). These results are consistent with the possibility that CBI-2 directly increases B8 excitability over the course of priming. Neither $1 \mathrm{mM}$ hexamethonium nor $100 \mu \mathrm{M}$ mecamylamine prevented the CBI-2-induced increase in B8 excitability $(53 \%$ and $28 \%$ increase in number of B8 spikes postpriming, respectively, $n=2$ for both). At these concentrations both pharmacological agents block nicotinic receptors in Aplysia (Hurwitz et al., 2003; White and Magoski, 2012), including those underlying the fast EPSPs from CBI-2 to B34 that we monitored in our experiments, suggesting that the effects of CBI-2 on B8 are consistent with the involvement of a muscariniclike receptor.

Progressive disinhibition controls the rate of expression of motor neuron excitability changes

Over the course of priming CBI-2 programs become progressively more ingestive, but the rate at which this change occurs involves at least two processes (a progressive increase in B8 excitability and a gradual decrease in B4/5 activity), making the rela- 


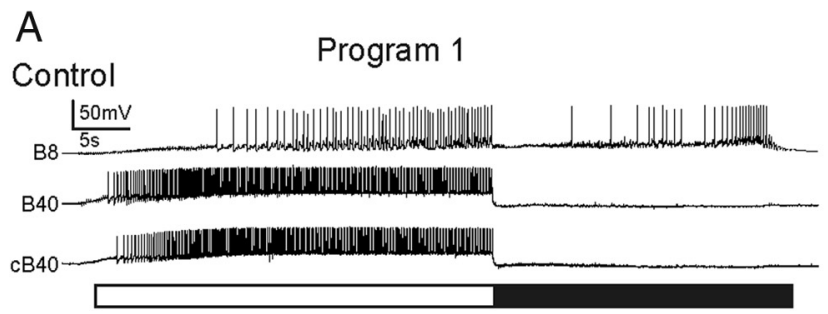

Program 10

Control

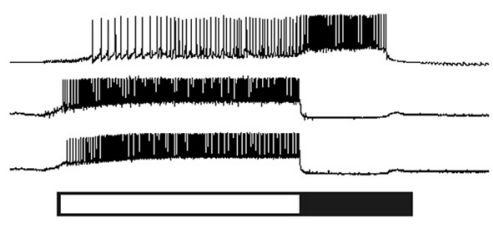

B40 Hyperpolarized
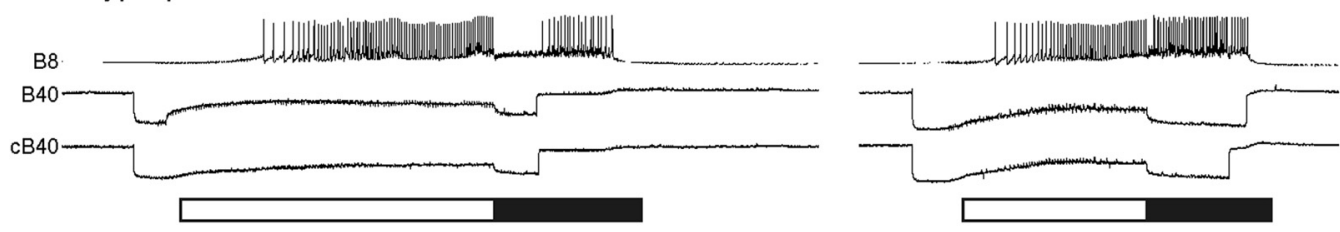

Recovery
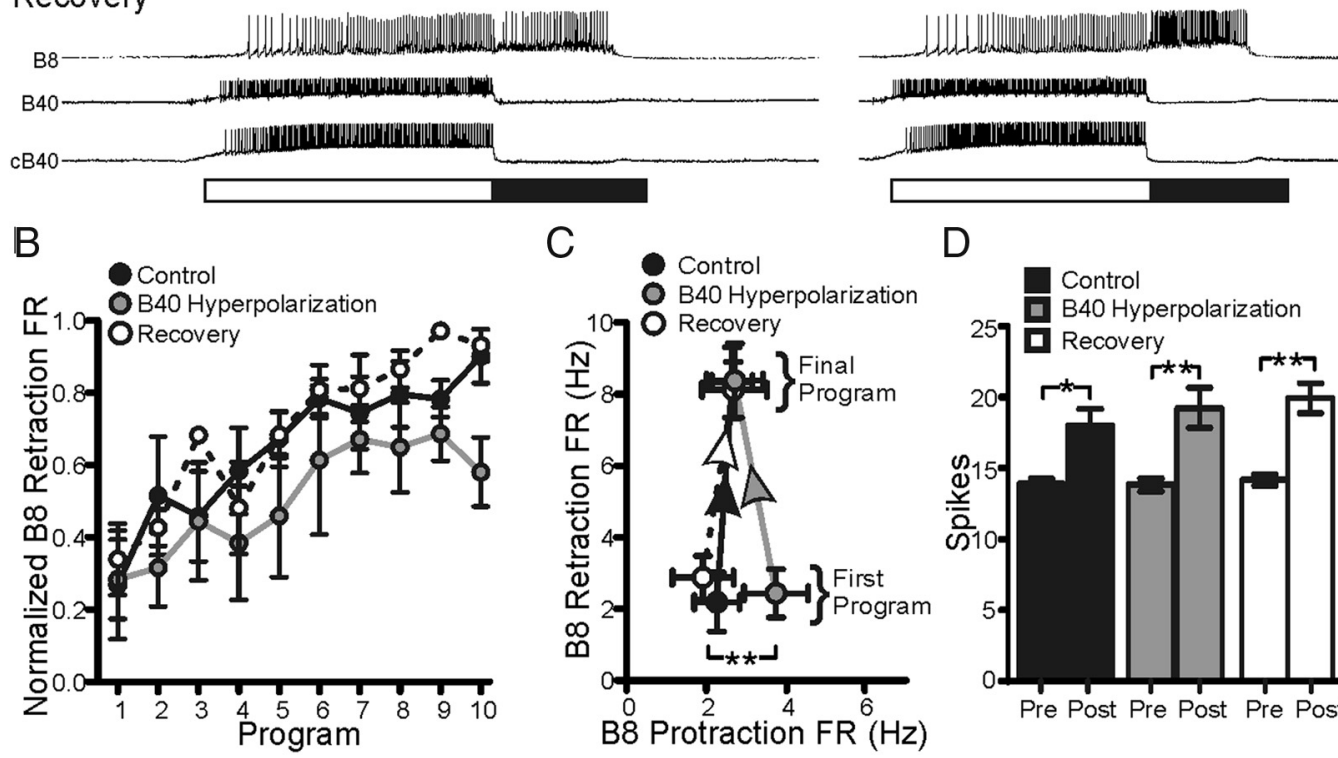

D
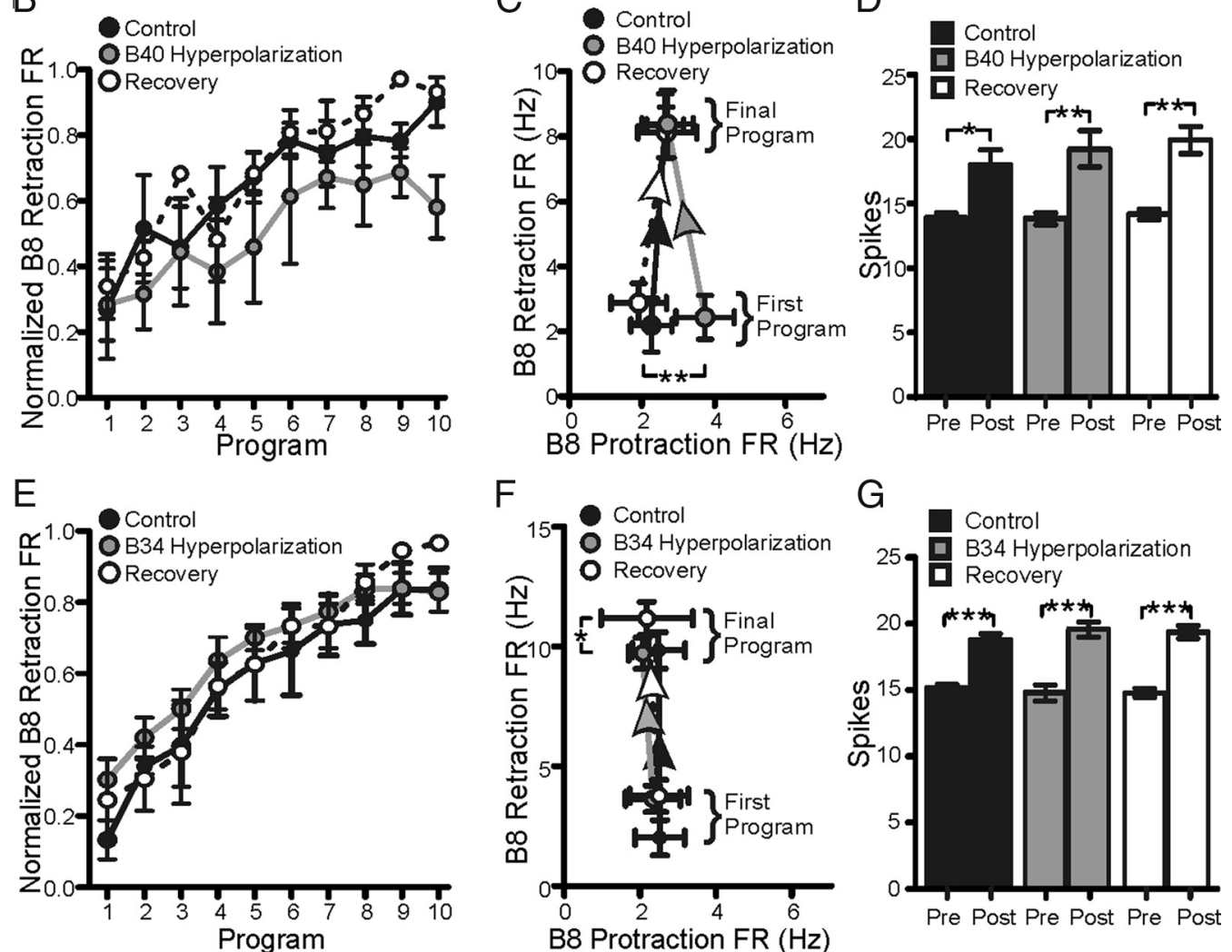

Figure 7. Neither B40 nor B34 activity is necessary for the (BI-2-elicited priming and the increase in B8 excitability. A, Representative traces of the 1st and 10th program during CBI-2 priming before (top), during (middle), and after B40 hyperpolarization (bottom). B, Normalized B8 retraction firing rate over the course of priming in which both B40s are hyperpolarized ("B40 Hyperpolarization") or are allowed to fire ("Control" and "Recovery"). C, B8 protraction and retraction firing rates (FR) in the first and final programs (brackets) for all three conditions do not differ. Because bilaterally hyperpolarizing B40 decreases B8 retraction firing rate in CBI-2 programs, B40 was allowed to fire during an additional 11th program to assess the extent to which priming had occurred. D, Repeated CBI-2 programs resulted in significant increases in B8 excitability in all conditions, but the amount of increase was not affected by hyperpolarization of B40. $\boldsymbol{E}$, Normalized B8 retraction firing rate over the course of priming in which both B34s are hyperpolarized ("B34 Hyperpolarization") or are allowed to fire ("Control" and "Recovery"). F, B8 protraction and retraction firing rates of the first and last programs (brackets) for all three conditions. G, Repeated (BI-2 programs significantly increase B8 excitability regardless of B34 participation in programs, but the amount of increase was not affected by hyperpolarization of $B 34\left({ }^{*} p<0.05,{ }^{* *} p<0.01,{ }^{* * *} p<0.001\right)$. 
A
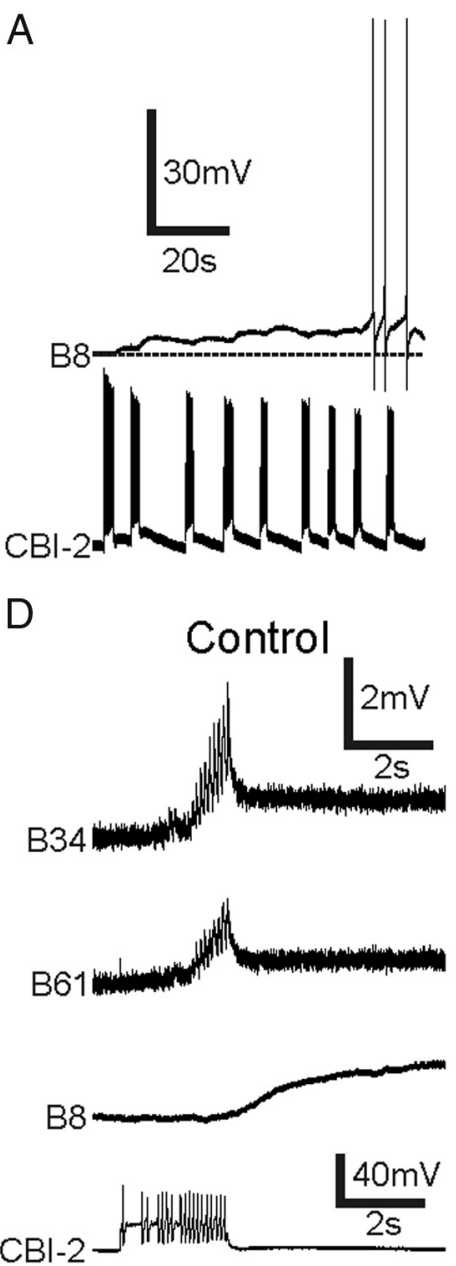

$E$

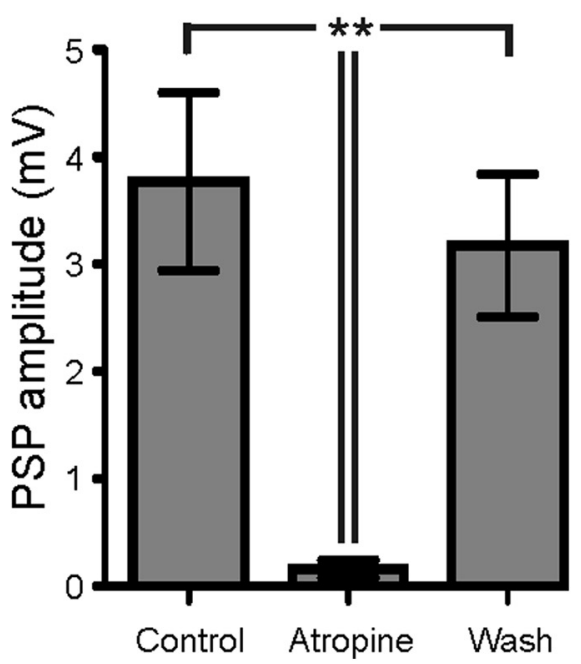

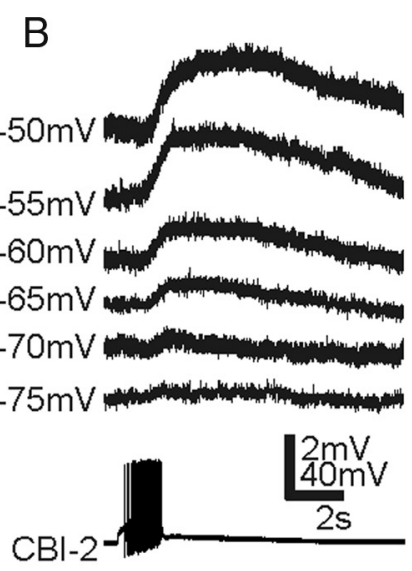

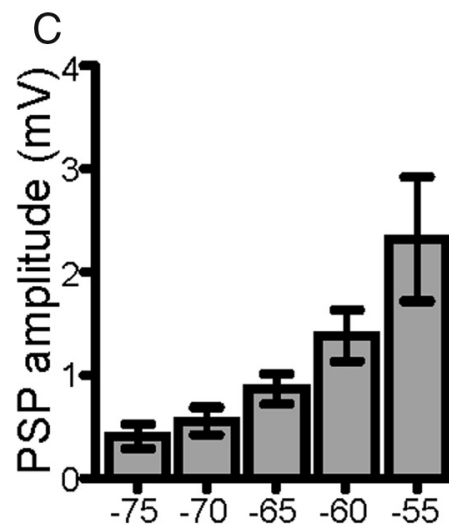

B8 holding potential
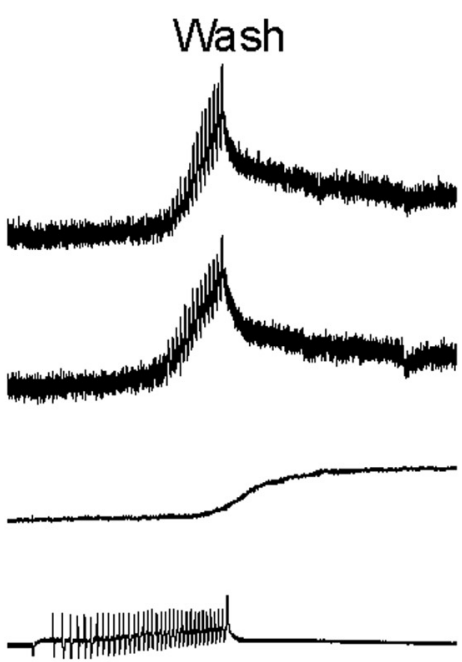

$\mathrm{F}$

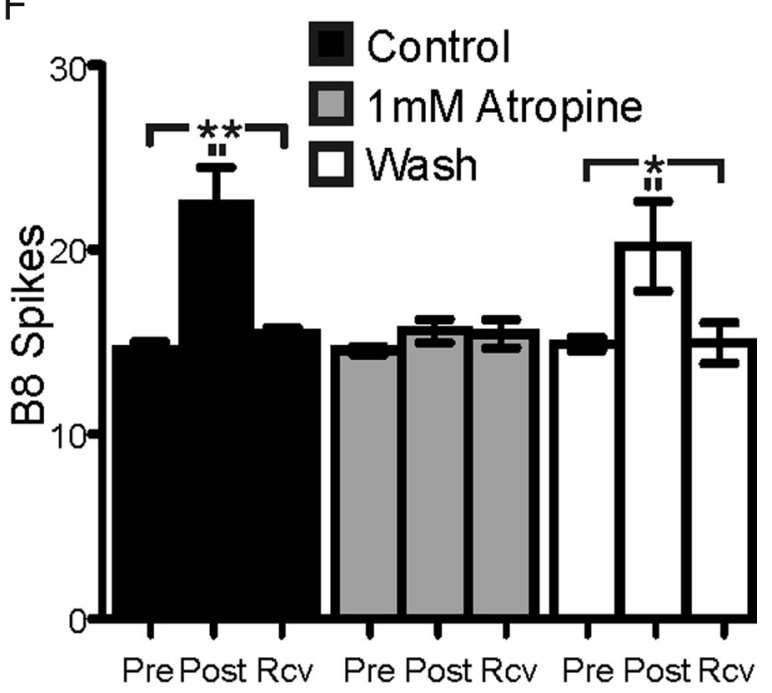

Figure 8. $\quad$ (BI-2 induces an atropine-sensitive depolarization of $\mathrm{B} 8$. $\boldsymbol{A}$, Brief bursts of $\mathrm{CBI}-2$ spikes induce a slow cumulative depolarization in B8. $\boldsymbol{B}$, The depolarization in $\mathrm{B} 8$ induced by $\mathrm{CBI}-2$ increases in amplitude as B8 membrane potential is depolarized. C, Average PSP amplitude over increasingly depolarized B8 membrane potentials. D, Representative traces depicting PSPs induced by (BI-2 in B8, B34, and B61 before (left), during (middle), and after (right) $1 \mathrm{~mm}$ atropine application. $\boldsymbol{E}$, Average B8 PSP height induced by (BI-2 before ("Control"), during ("Atropine") and after ("Wash") $1 \mathrm{~mm}$ atropine application. $\boldsymbol{F}$, The increase in B8 excitability induced by (BI-2 is blocked in the presence of $1 \mathrm{~mm}$ atropine $\left({ }^{*} p<0.05,{ }^{* *} p<0.01\right)$.

tive contributions of each process to the dynamics of network output unclear. We therefore sought to determine the extent to which $\mathrm{B} 4 / 5$ activity shapes the dynamics of ingestive priming. A single CBI-2 program was induced to probe the default network state ("pre"); then, after a 10 min rest period, priming was induced while, during each retraction phase, the ipsilateral B4/5 were prevented from firing by injections of hyperpolarizing current. After 10 programs, a final CBI-2 program ("post") was trig- 

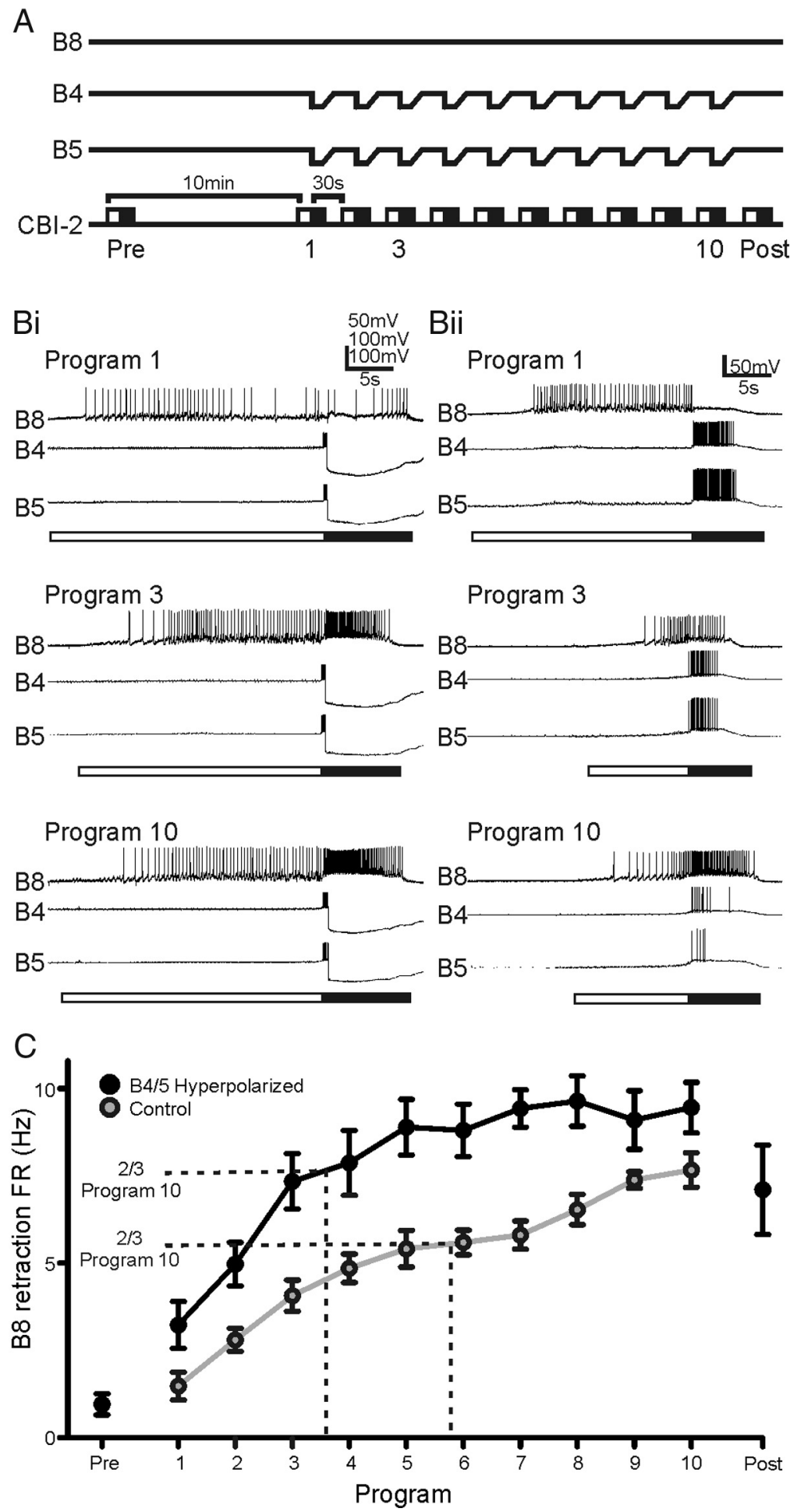

Figure 9. Hyperpolarizing $B 4 / 5$ increases the rate at which priming is expressed. $A$, Experimental protocol. A single (BI-2 program (white and black box) is elicited and then the preparation is allowed to rest for $10 \mathrm{~min}$ to prevent CBI-2 priming. $\mathrm{CBI}-2$ priming is then induced by eliciting $10 \mathrm{CBI}-2$ programs with $\mathrm{B} 4 / 5$ hyperpolarized at the onset of retraction. An 11 th program is elicited to compare the contribution of $B 4 / 5$ at the end of priming. The preparation is allowed to recover and then $(B I-2$ priming is induced again to allow for comparison with rounds of priming in which $B 4 / 5$ are hyperpolarized. $\boldsymbol{B}$, Biting motor programs (programs 1, 3, and 10) elicited by (BI-2 with B4/5 hyperpolarized (Bi) or B4/5 permitted to fire during retraction (Bii). The discrepancy between $B 8$ retraction firing rate for bouts of priming is most striking during program 3. C, Average B8 retraction firing rate (FR) over the course of priming when $B 4 / 5$ are hyperpolarized during retraction ("B4/5 Hyperpolarized"; black) and when B4/5 are permitted to fire during protraction ("Control"; gray). Hatched lines indicate two-thirds of the B8 retraction firing rate during program 10 for each treatment. gered in which $\mathrm{B} 4 / 5$ were permitted to participate (Fig. 9A). The preparation was allowed to recover, and another round of priming was induced to compare the rate at which $\mathrm{B} 8$ retraction activity increased when $\mathrm{B} 4 / 5$ were permitted to fire during retraction. Example recordings of the 1st, $3 \mathrm{rd}$, and 10th programs during both rounds of priming are depicted in Figure $9 B$. B8 firing rate before priming did not differ between trials in which B4/5 was hyperpolarized (pre) and control trials (program 1), indicating that during both rounds of priming the baseline state was similar (Fig. 9C). Furthermore, B8 retraction firing rate in the additional program triggered after a round of priming in which B4/5 were hyperpolarized (post) did not differ from the final program of control rounds of build-up (Fig. 9C), suggesting that $\mathrm{B} 4 / 5$ hyperpolarization does not produce long-term effects on network output.

During the 1st program of CBI-2 priming (Fig. 9B; program 1), B8 retraction firing rate was only slightly higher with B4/5 hyperpolarized. However, by the 3rd program (Fig. $9 B$; program 3 ), B8 retraction firing rate was dramatically higher when B4/5 were hyperpolarized compared to control trials. By the 10th program (Fig. 9B; "Program 10") B8 retraction firing rate was similar under both conditions, a result consistent with the decrease in B4/5 activity observed when the network was primed under control conditions. A two-way repeated-measures ANOVA revealed that B8 retraction firing rate was not significantly different for the first two and last two programs when B4/5 was hyperpolarized compared to controls. Therefore no significant interaction was observed between program number and treatment when programs 1-10 were analyzed under the two conditions. However, to determine whether removing the influence of B4/5 caused B8 retraction firing rate to approach "primed" levels sooner, we calculated the number of programs necessary surpass $66 \%$ of $\mathrm{B} 8$ retraction firing rate in program 10 (Fig. 9C) for both groups. On average, the $66 \%$ threshold was surpassed significantly sooner (paired $t$ test $t=2.994, \mathrm{df}=4, p<0.05$ ) when $B 4 / 5$ were hyperpolarized ( $3.6 \pm 0.6$ programs SEM) compared to control rounds of priming $(5.8 \pm 0.9$ programs SEM). This suggests that although the increase in B8 excitability may occur relatively rapidly, inhibition by B4/5 delays its expression in network output. Thus, the rate with which $\mathrm{B} 8$ activity increases over the course of CBI- 2 priming is the product 
of two processes: the induction of excitability changes in $\mathrm{B} 8$, and the gating of the expression of these excitability changes by the removal of inhibitory input from B4/5 to B8.

\section{Discussion}

As we interact with our environment, recent experiences bias our responses to the stimuli we encounter by establishing a historydependent internal state. At the cellular level, the nature of these states and the transitions between them involve multiple processes that occur on different timescales. The goal of this study was to determine the nature of the cellular mechanisms that mediate the transition from a default/baseline network state to a primed network state. We found that to produce primed behavior from the default state, the nervous system progressively removes an active suppression of network output and increases the excitability of output neurons, thus resulting in enhanced responses. This indicates that the establishment of a network state involves the inactivation of processes present in the default state as well as the activation of processes associated with recent network activation.

The concept of the "default state" arose from the observation that there were decreases (in addition to increases) in the brain activity of human subjects as they began a task from either having their eyes closed at rest or conditions of visual fixation (Shulman et al., 1997; Gusnard et al., 2001; Raichle et al., 2001; Raichle and Snyder, 2007). While the observed increases tended to be in task specific areas of the brain, the decreases tended to be task independent in their location (Shulman et al., 1997), suggesting that before a task is initiated there exists an "organized, baseline default mode of brain function that is suspended during specific goal-directed behaviors" (Raichle et al., 2001). Repetition priming is particularly well suited to study the establishment of a network state from a default state, as neuroimaging (Squire et al., 1992; Buckner et al., 1995) and electrophysiological studies (Miller et al., 1991; Li et al., 1993; Miller and Desimone, 1994; Badgaiyan and Posner, 1997) have reported a "repetition suppression" in which the priming of a behavior accompanies a decrease in brain activation in response to the primed stimuli. Repetition suppression has been hypothesized to be a manifestation of an increase in the efficiency with which the brain responds to a previously encountered stimulus (Henson, 2003) and may therefore represent a removal of active suppression enforced by the default state that could regulate network output based on the level of inhibition exerted (Buzsáki et al., 2007).

In the nervous system of Aplysia, we demonstrate that a suppression of interneuronal firing strongly contributes to the generation of primed motor output. Over the course of ingestive priming, we observed a dramatic decrease in the activity of neurons $(\mathrm{B} 4 / 5)$ that inhibit motor neurons (B8) that implement the closure of the mouthparts (Fig. 3A, B). Restoring the inhibitory drive exerted by $\mathrm{B} 4 / 5$ significantly decreased $\mathrm{B} 8$ firing rate (Fig. 4), although not to prepriming levels (due to the increase in B8 excitability also induced by priming). Based on previous parametric studies, the reduced B8 activity would produce much weaker biting (Jing and Weiss, 2005; Friedman et al., 2009) despite the changes in B8 excitability, demonstrating the contribution of disinhibition to the functional expression of network output. Disinhibition is a widespread mechanism employed by the nervous system to regulate behavior and can involve the removal of tonic or phase-specific inhibition, endowing the nervous system with a large degree of control over the threshold for the production of a behavior ( $\mathrm{Vu}$ and Krasne, 1993; $\mathrm{Vu}$ et al., 1993; Staras et al., 2003) or even the phase-specific properties of the behavior itself (Pinaud et al., 2008). On a very basic level the progressive decrease in B4/5 input to B8 represents a historydependent conditional gating mechanism for the expression of network dynamics that occur during the establishment of an internal state. The strength of this gating mechanism suggests that the default state should not be considered merely a passive state from which the network is activated.

Several lines of evidence suggested that a mechanism in addition to disinhibition contributes to the increase in $\mathrm{B} 8$ retraction activity during priming: (1) for several minutes after priming, B8 spikes spontaneously; (2) depolarizing B4/5 postpriming does not decrease B8 retraction activity to prepriming levels (Fig. 4); and finally, (3) hyperpolarizing B4/5 in unprimed animals does not cause B8 retraction firing rate to reach postpriming levels (Fig. 9). Specifically, we observed a persistent increase in B8 excitability postpriming (Fig. 6). Excitability modulation has been demonstrated in a number of systems as a mechanism by which recent history can implement longer lasting temporal dynamics in the response properties of a neuron (Byrne and Kandel, 1996; Destexhe and Marder, 2004; Baroni et al., 2010; Steinert et al., 2011). Our data, in combination with previous work on the cellular mechanisms underlying repetition priming (Friedman and Weiss, 2010), suggest that multiple mechanisms induce changes in motor neuron excitability and that their implementation may be segregated based on functional traits of target motor neurons. Because multiphasic behaviors involve the coordination of movements in a specific sequence, improvements in the implementation of a multiphasic behavior require increased motor output of antagonistic muscle groups to be antiphasic. During ingestive priming in Aplysia, the radula closure motor neuron B8 preferentially increases its firing rate during retraction phase, while the radula opener motor neuron B48 increases its firing rate during protraction (Proekt et al., 2004; Friedman et al., 2009). Thus, the activity of motor neurons coordinating antagonistic movements increases during different phases of the behavior. For both B48 (Friedman and Weiss, 2010) and B8 (Fig. 6), priming results in an increase in excitability, yet several differences in the nature of these increases suggest different underlying mechanisms. The excitability changes in B48 are induced by FCAP and $\mathrm{CP} 2$, the neuropeptides released by CBI-2, yet these neuropeptides do not affect B8 excitability (Friedman and Weiss, 2010). Furthermore, the CBI-2 stimulation protocol sufficient to induce the excitability changes in B48 was not sufficient to affect B8 excitability (Friedman and Weiss, 2010). Finally, the magnitude of the excitability change induced by CBI- 2 is much larger in B48 (Friedman and Weiss, 2010) relative to B8 (Fig. 6). These different mechanisms may represent different forms of control implemented on the basis of functional features of the different motor neurons. B48 is only active during protraction, and thus a large and rapid increase in excitability provides a simple yet elegant solution to increase its activity in only one phase. B8, on the other hand, is active across both phases, and therefore the network may require greater control over the expression of changes in B8 excitability. This could explain why the effect of priming on the biophysical properties of $\mathrm{B} 8$ was smaller compared to B48, and the expression of the modulation of B8 excitability (manifested as an increased firing rate) was conditional upon the removal of gating inhibition from $\mathrm{B} 4 / 5$.

Unexpectedly, the increase in B8 excitability did not affect B8 protraction firing rate during priming (Fig. $1 B$ ). This could be because the protraction neurons $\mathrm{B} 40$ and $\mathrm{B} 34$ provide potent shunting inhibition to B8 during protraction (Jing and Weiss, 2002; Jing et al., 2003), resulting in a high conductance state 
(Sasaki et al., 2009) that could alter the slope of B8's input-output relationship (Destexhe, 2010). It is therefore conceivable that shunting inhibition reduces the potency of the observed excitability change in a phase-specific manner. Likewise, disinhibition of B8 via the decrease in B4/5 retraction activity likely represents a phase-specific transition from a high to a low conductance state that would be further augmented by the low conductance slow EPSPs elicited by B40 and B34 in the retraction phase (Jing and Weiss, 2002), thus gating the expression of the excitability changes in B8. Additionally, the synaptic input to B8 during protraction may change. For instance, there is a small increase in the protraction firing rate of $\mathrm{B} 40$ (Fig. $5 A, B$ ), potentially increasing the inhibitory drive to $\mathrm{B} 8$ during protraction.

The present study has focused on the convergence of multiple mechanisms in the production of state-dependent control of network output. Our results demonstrate that transition from the default to a primed network state involves both additive and subtractive mechanisms with regard to network activity. One mechanism, the history-dependent modulation of motoneuronal excitability, provides slow temporal dynamics to the enhancement of motor output seen during successive responses to similar environmental stimuli. This aspect of state transition represents the activation of additional processes not present in the default state. The second mechanism, disinhibition of motor output, allows the changes in motoneuronal biophysical properties to be conditionally expressed, and may facilitate the articulation of well tuned behavioral responses. This mechanism represents the inactivation of processes present in the default state. The importance of disinhibition in the priming of feeding responses emphasizes the notion that establishment of a motivational state involves the transition between two active states, rather than simple activation from a passive baseline. These results reinforce the notion that even when the identity and connections of many neurons in a neural network are known, the network output in response to a constant stimulus cannot be adequately predicted without an understanding of the cellular processes underlying different network states (Selverston, 1980; Nadim et al., 2008; Brezina, 2010).

\section{References}

Badgaiyan RD, Posner MI (1997) Time course of cortical activations in implicit and explicit recall. J Neurosci 17:4904-4913. Medline

Ballo AW, Bucher D (2009) Complex intrinsic membrane properties and dopamine shape spiking activity in a motor axon. J Neurosci 29:50625074. CrossRef Medline

Ballo AW, Nadim F, Bucher D (2012) Dopamine modulation of Ih improves temporal fidelity of spike propagation in an unmyelinated axon. J Neurosci 32:5106-5119. CrossRef Medline

Baroni F, Torres JJ, Varona P (2010) History-dependent excitability as a single-cell substrate of transient memory for information discrimination. PLoS One 5:e15023. CrossRef Medline

Berg RW, Hounsgaard J (2009) Signaling in large-scale neural networks. Cogn Process [10 Suppl] 1:S9-S15. CrossRef Medline

Brezina V (2010) Beyond the wiring diagram: signalling through complex neuromodulator networks. Philos Trans R Soc Lond B Biol Sci 365:23632374. CrossRef Medline

Buckner RL, Petersen SE, Ojemann JG, Miezin FM, Squire LR, Raichle ME (1995) Functional anatomical studies of explicit and implicit memory retrieval tasks. J Neurosci 15:12-29. Medline

Buzsáki G, Kaila K, Raichle M (2007) Inhibition and brain work. Neuron 56:771-783. CrossRef Medline

Byrne JH, Kandel ER (1996) Presynaptic facilitation revisited: state and time dependence. J Neurosci 16:425-435. Medline

Destexhe A (2010) Inhibitory "noise." Front Cell Neurosci 4:9. CrossRef Medline

Destexhe A, Marder E (2004) Plasticity in single neuron and circuit computations. Nature 431:789-795. CrossRef Medline
Devor A (2002) The great gate: control of sensory information flow to the cerebellum. Cerebellum 1:27-34. CrossRef Medline

Fontanini A, Katz DB (2008) Behavioral states, network states, and sensory response variability. J Neurophysiol 100:1160-1168. CrossRef Medline

Friedman AK, Weiss KR (2010) Repetition priming of motoneuronal activity in a small motor network: intercellular and intracellular signaling. J Neurosci 30:8906-8919. CrossRef Medline

Friedman AK, Zhurov Y, Ludwar BCh, Weiss KR (2009) Motor outputs in a multitasking network: relative contributions of inputs and experiencedependent network states. J Neurophysiol 102:3711-3727. CrossRef Medline

Gardner D (1977) Interconnections of identified multiaction interneurons in buccal ganglia of Aplysia. J Neurophysiol 40:349-361. Medline

Gardner D, Kandel ER (1977) Physiological and kinetic properties of cholinergic receptors activated by multiaction interneurons in buccal ganglia of Aplysia. J Neurophysiol 40:333-348. Medline

Gusnard DA, Akbudak E, Shulman GL, Raichle ME (2001) Medial prefrontal cortex and self-referential mental activity: relation to a default mode of brain function. Proc Natl Acad Sci U S A 98:4259-4264. CrossRef Medline

Heinrich R, Wenzel B, Elsner N (2001) Pharmacological brain stimulation releases elaborate stridulatory behaviour in gomphocerine grasshoppersconclusions for the organization of the central nervous control. J Comp Physiol A 187:155-169. CrossRef Medline

Henson RN (2003) Neuroimaging studies of priming. Prog Neurobiol 70: 53-81. CrossRef Medline

Hurwitz I, Susswein AJ (1996) B64, a newly identified central pattern generator element producing a phase switch from protraction to retraction in buccal motor programs of Aplysia californica. J Neurophysiol 75:13271344. Medline

Hurwitz I, Neustadter D, Morton DW, Chiel HJ, Susswein AJ (1996) Activity patterns of the $\mathrm{B} 31 / \mathrm{B} 32$ pattern initiators innervating the I2 muscle of the buccal mass during normal feeding movements in Aplysia californica. J Neurophysiol 75:1309-1326. Medline

Hurwitz I, Kupfermann I, Susswein AJ (1997) Different roles of neurons $\mathrm{B} 63$ and B34 that are active during the protraction phase of buccal motor programs in Aplysia californica. J Neurophysiol 78:1305-1319. Medline

Hurwitz I, Perrins R, Xin Y, Weiss KR, Kupfermann I (1999) C-PR neuron of Aplysia has differential effects on "Feeding" cerebral interneurons, including myomodulin-positive CBI-12. J Neurophysiol 81:521-534. Medline

Hurwitz I, Kupfermann I, Weiss KR (2003) Fast synaptic connections from CBIs to pattern-generating neurons in Aplysia: initiation and modification of motor programs. J Neurophysiol 89:2120-2136. Medline

Jing J, Weiss KR (2001) Neural mechanisms of motor program switching in Aplysia. J Neurosci 21:7349-7362. Medline

Jing J, Weiss KR (2002) Interneuronal basis of the generation of related but distinct motor programs in Aplysia: implications for current neuronal models of vertebrate intralimb coordination. J Neurosci 22:6228-6238. Medline

Jing J, Weiss KR (2005) Generation of variants of a motor act in a modular and hierarchical motor network. Curr Biol 15:1712-1721. CrossRef Medline

Jing J, Vilim FS, Wu JS, Park JH, Weiss KR (2003) Concerted GABAergic actions of Aplysia feeding interneurons in motor program specification. J Neurosci 23:5283-5294. Medline

Kabotyanski EA, Baxter DA, Byrne JH (1998) Identification and characterization of catecholaminergic neuron $\mathrm{B} 65$, which initiates and modifies patterned activity in the buccal ganglia of Aplysia. J Neurophysiol 79:605621. Medline

Koh HY, Vilim FS, Jing J, Weiss KR (2003) Two neuropeptides colocalized in a command-like neuron use distinct mechanisms to enhance its fast synaptic connection. J Neurophysiol 90:2074-2079. CrossRef Medline

Lennard PR, Getting PA, Hume RI (1980) Central pattern generator mediating swimming in Tritonia. II. Initiation, maintenance, and termination. J Neurophysiol 44:165-173. Medline

Li L, Miller EK, Desimone R (1993) The representation of stimulus familiarity in anterior inferior temporal cortex. J Neurophysiol 69:1918-1929. Medline

Ménard A, Grillner S (2008) Diencephalic locomotor region in the lamprey-afferents and efferent control. J Neurophysiol 100:1343-1353. CrossRef Medline 
Miller EK, Desimone R (1994) Parallel neuronal mechanisms for shortterm memory. Science 263:520-522. CrossRef Medline

Miller EK, Li L, Desimone R (1991) A neural mechanism for working and recognition memory in inferior temporal cortex. Science 254:1377-1379. CrossRef Medline

Morgan PT, Perrins R, Lloyd PE, Weiss KR (2000) Intrinsic and extrinsic modulation of a single central pattern generating circuit. J Neurophysiol 84:1186-1193. Medline

Morton DW, Chiel HJ (1993a) In vivo buccal nerve activity that distinguishes ingestion from rejection can be used to predict behavioral transitions in Aplysia. J Comp Physiol A 172:17-32. CrossRef Medline

Morton DW, Chiel HJ (1993b) The timing of activity in motor neurons that produce radula movements distinguishes ingestion from rejection in Aplysia. J Comp Physiol A 173:519-536. CrossRef Medline

Nadim F, Brezina V, Destexhe A, Linster C (2008) State dependence of network output: modeling and experiments. J Neurosci 28:11806-11813. CrossRef Medline

Nargeot R, Baxter DA, Byrne JH (1999a) In vitro analog of operant conditioning in Aplysia. I. Contingent reinforcement modifies the functional dynamics of an identified neuron. J Neurosci 19:2247-2260. Medline

Nargeot R, Baxter DA, Byrne JH (1999b) In vitro analog of operant conditioning in Aplysia. II. Modifications of the functional dynamics of an identified neuron contribute to motor pattern selection. J Neurosci 19: 2261-2272. Medline

Perrins R, Walford A, Roberts A (2002) Sensory activation and role of inhibitory reticulospinal neurons that stop swimming in hatchling frog tadpoles. J Neurosci 22:4229-4240. Medline

Pinaud R, Terleph TA, Tremere LA, Phan ML, Dagostin AA, Leão RM, Mello CV, Vicario DS (2008) Inhibitory network interactions shape the auditory processing of natural communication signals in the songbird auditory forebrain. J Neurophysiol 100:441-455. CrossRef Medline

Proekt A, Weiss KR (2003) Convergent mechanisms mediate preparatory states and repetition priming in the feeding network of Aplysia. J Neurosci 23:4029-4033. Medline

Proekt A, Brezina V, Weiss KR (2004) Dynamical basis of intentions and expectations in a simple neuronal network. Proc Natl Acad Sci U S A 101:9447-9452. CrossRef Medline

Proekt A, Jing J, Weiss KR (2007) Multiple contributions of an inputrepresenting neuron to the dynamics of the Aplysia feeding network. J Neurophysiol 97:3046-3056. CrossRef Medline

Raichle ME, Snyder AZ (2007) A default mode of brain function: a brief history of an evolving idea. Neuroimage 37:1083-1090; discussion 10971099. CrossRef Medline

Raichle ME, MacLeod AM, Snyder AZ, Powers WJ, Gusnard DA, Shulman GL (2001) A default mode of brain function. Proc Natl Acad Sci U S A 98:676-682. CrossRef Medline

Rosen SC, Teyke T, Miller MW, Weiss KR, Kupfermann I (1991) Identifi- cation and characterization of cerebral-to-buccal interneurons implicated in the control of motor programs associated with feeding in Aplysia. J Neurosci 11:3630-3655. Medline

Sakurai A, Katz PS (2009) State-, timing-, and pattern-dependent neuromodulation of synaptic strength by a serotonergic interneuron. J Neurosci 29:268-289. CrossRef Medline

Sasaki K, Brezina V, Weiss KR, Jing J (2009) Distinct inhibitory neurons exert temporally specific control over activity of a motoneuron receiving concurrent excitation and inhibition. J Neurosci 29:11732-11744. CrossRef Medline

Selverston AI (1980) Are central pattern generators understandable? Behav Brain Sci 3:535-540. CrossRef

Shulman GL, Fiez JA, Corbetta M, Buckner RL, Miezin FM, Raichle ME, Petersen SE (1997) Common blood flow changes across visual tasks. 2. Decreases in cerebral cortex. J Cogn Neurosci 9:648-663. CrossRef

Squire LR, Ojemann JG, Miezin FM, Petersen SE, Videen TO, Raichle ME (1992) Activation of the hippocampus in normal humans: a functional anatomical study of memory. Proc Natl Acad Sci U S A 89:1837-1841. CrossRef Medline

Staras K, Kemenes I, Benjamin PR, Kemenes G (2003) Loss of selfinhibition is a cellular mechanism for episodic rhythmic behavior. Curr Biol 13:116-124. CrossRef Medline

Steinert JR, Robinson SW, Tong H, Haustein MD, Kopp-Scheinpflug C, Forsythe ID (2011) Nitric oxide is an activity-dependent regulator of target neuron intrinsic excitability. Neuron 71:291-305. CrossRef Medline

Susswein AJ, Byrne JH (1988) Identification and characterization of neurons initiating patterned neural activity in the buccal ganglia of Aplysia. J Neurosci 8:2049-2061. Medline

Susswein AJ, Weiss K, Kupfermann I (1978) The effects of food arousal on latency of biting in Aplysia. J Comp Physiol A 123:31-41. CrossRef

Vilim FS, Alexeeva V, Moroz LL, Li L, Moroz TP, Sweedler JV, Weiss KR (2001) Cloning, expression and processing of the CP2 neuropeptide precursor of Aplysia. Peptides 22:2027-2038. CrossRef Medline

Vu ET, Krasne FB (1993) Crayfish tonic inhibition: prolonged modulation of behavioral excitability by classical GABAergic inhibition. J Neurosci 13:4394-4402. Medline

Vu ET, Lee SC, Krasne FB (1993) The mechanism of tonic inhibition of crayfish escape behavior: distal inhibition and its functional significance. J Neurosci 13:4379-4393. Medline

Weiss K, Koch U, Koester J, Mandelbaum DE, Kupfermann I (1981) Neural and molecular mechanisms of food-induced arousal in Aplysia californica. Adv Physiol Sci 23:305-344.

Wenzel B, Elsner N, Heinrich R (2002) mAChRs in the grasshopper brain mediate excitation by activation of the AC/PKA and the PLC secondmessenger pathways. J Neurophysiol 87:876-888. Medline

White SH, Magoski NS (2012) Acetylcholine-evoked afterdischarge in Aplysia bag cell neurons. J Neurophysiol 107:2672-2685. CrossRef Medline 